\title{
An Overview of Childhood Obesity: the Health Issue
}

\author{
Jasleen Kaur and Meena \\ Shree Guru Gobind Singh Tricentary University, Gurugram, Haryana, India \\ Corresponding author email: jasleenkaur_fmhs@sgtuniversity.org
}

\begin{abstract}
Childhood obesity has reached to its epidemic level in most of the developed as well as developing countries. The childhood obesity and overweight have significant negative impact on both physiological and physical health. Obesity and overweight in children can cause of non-communicable diseases such as cardiovascular disease and diabetes. The mechanism of childhood obesity is still not fully cleared yet and it believed that multiple causes can be possible such as lifestyle, environmental factor and eating habits. Overall, obesity and overweight depends on the fat and caloric intake. Apart from this, sugar consumption though soft drinks slowly decline the physical activity resulting in weight gain and obesity. This review article will discuss about the childhood obesity causes, related risk factors and preventive measures that can take to reduce the childhood obesity problem. In order to reduce the chances of obesity and overweight in such an early age, healthy lifestyle and physical activities needs to be promoted in schools as well as at home.
\end{abstract}

KEY W ORDS: BODY MASS INDEX (BMI), CHILDHOOD OBESITY, CARDIOVASCULAR DISEASE, DIABETES, MULTI-SYSTEM DISEASE.

\section{INTRODUCTION}

These days most of the countries are facing the overweight and obesity health issues in children. All over the world, approximately 22 million children $(<5$ years age) are suffering from overweight and obesity problem. The cases of childhood obesity increasing day by day due to the unhealthy lifestyle among the children(J. Lanigan et. al. 2019)). Obesity and overweight in children promotes the other diseases such as bones related diseases, heart related diseases and diabetes that can make the life shorter. In today's technological world, most of the children spend lots of time on computers, video games and television viewing(S. R. Daniels et. al. 2006). Due to lack of physical activity or exercise, the overweight and obesity health issue improve significantly. Another factor that enhances the chance of obesity in children is consumption of unhealthy food (i.e. junk food with high fat and less nutrition). The food companies aggressively promote the junk food among

Biosc Biotech Res Comm P-ISSN: 0974-6455 E-ISSN: 2321-4007

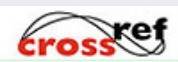

Identifiers and Pagination

Year: 2021 Vol: 14 No (7) Special Issue

Pages: $288-291$

This is an open access article under Creative

Commons License Attribn 4.0 Intl (CC-BY). DOI: $h t t p: / / d x$.doi.org/10.21786/bbrc/14.7.63 the youngster and children that creates a bad impact on their mind and starts attracting towards the junk food(A. Bhadoria et. al. 2015).

In order to overcome the problem of overweight and obesity in children, physical activity and healthy food can help to suppress the effect. Prevention is always better than treatment of obesity in children. By adapting the organized and healthy lifestyle with exercise in home and school, the problem can be overcome in effective way(J. GrantGuimaraes et. al. 2016)). The social intervention can play a critical role for prevention of childhood obesity. It must be ensuring that the food that is provided to the children must have balanced nutrition. Schools must introduce the physical education in the curriculum that can help students' to be physically fit.

This review article provides an overview of overweight and obesity health problem in children. The article mainly discussed about the mechanism of the obesity and causes that helps to promote the obesity in children. After those diagnosis methods, prevention and treatments of the childhood obesity will be discussed.

Mechanism Of Obesity: During the growth of the child, the number of fat cells increases and when the calorie consumption exceeds the expenditure, the size of the fat cell is also increases. When the size of the fat cell reached to its maximum size and calorie intake continues and exceeds the

\section{Article Information}

Received: $10^{\text {th }}$ May 2021 ccepted after revision: $14^{\text {th }}$ July 2021 
energy expenditure, the numbers of the fat cells increases further. During the weight/fat loss, the size of the fat cells reduces and shrinks but the number remains same(E. N. Whitney et. al. 2002)). The calorie consumption by any means must be in control manner. Excessive consumption of the calories without physical activity leads to the obesity problem. If any person consumes lots of calories, it must be ensure that physical activity must introduce in the daily routine to avoid excessive weight gain and obesity.

There are some fatty acids in the form of triglycerides found in the food or in the body. Triglycerides consists of three fatty acids that are attached to a glycerol molecule. Triglycerides are formed due to theseries of condensation reactions that takes place between the fatty acids and hydrogen atom from the glycerol molecule and release a water molecule. Triglycerides are found in most of the food products in order to protect them from oxidation. The main drawback associated with triglycerides is that they convert poly-saturated fats into more saturated form. Due to this conversion, the advantage of consuming that food lost during the process of hydrogenation and food textures are also altered(E. N. Whitney et. al. 2002)). Triglyceride fatty acid leads to the weight gain due to the conversion of poly-saturated fats into saturated fat.

In one research, it has been shown that obesity caused due to the increase in hormone (called leptin) level. The leptin is generated from a fat tissue called adipose and this hormone is responsible for the regulation of food intake, energy expenditure and energy balance in the humans $(\mathrm{O}$. Moran et. al. 2003)).. These days childhood obesity is most common among the children due to the metabolic and nutritional disease. In a study, researchers showed that, from 1981 to 1996 , the obesity rate increase in boys and girls were $17 \%$ and $15 \%$ respectively. Childhood obesity is a major problem is western countries(N.M. Jadavjiet. al. 2006)). In most of the western countries, children consume high calorie food that leads to the variation in leptin hormone resulting in imbalance of energy expenditure.

Causes Of Obesity: It has been observed that there are three main causes of childhood obesity such as lack of physical activity or exercise, overeating and genetics. Obesity is just not a result of single factor, it causes due to the combination of these factors because these factors are interrelated (Figure 1).

Figure 1: Schematic illustration of Main Causes of Obesity

Genetics

Overeating
Causes of Obesity

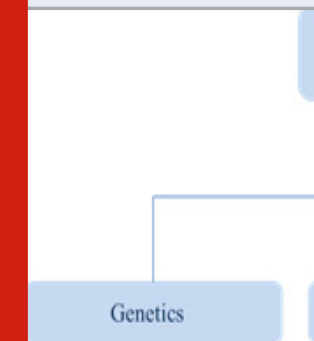

$$
\text { Causes of Obesity }
$$
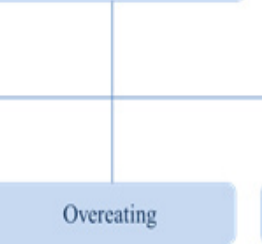

Lack of physical activity
1. Genetics: Genetics can be one of the cause of obesity in children but it's very rare to contribute to obesity. Due to hormones, there are only $1 \%$ chance of obesity. The genetically affected children feel extremely hungry all the time and become obese due to the overeating(N.M. Jadavjiet. al. 2006)). In order to overcome such problem, right support and guidance can help children to work efficiently and keep the weight within the healthy range.

2. Lack of Physical activity: The second factor that causes obesity in children is lack of physical activity or exercise. In today's technological world, most of the kids have habit to stick to the mobile or any other electronic gadgets. The lack of physical activity is due to the lack of emphasis on physical education in school and at home. It has been noticed that there has been a decline in the interest to play sports or any other physical activity involved games(C. D. C. Anrig al. 2003)). Obesity can also cause by unorganized physical activity or exercise. The risk of obesity in children can be reduced by at least from $23 \%$ to $43 \%$ due to physical activity. On the other hand, the overweight can be increased by $17 \%$ to $44 \%$ because of time spending on electric gadgets that can increase the risk of obesity from $10 \%$ to $61 \%$ (M.S. Tremblay et. al. (2000)). Physical activity in the children makes them more active and reduces the chance of obesity and weight gain even consumes high calorie food.

Watching television is a major factor to improve obesity in children. It has long term effect in life. The Canadian children from 7 year to 12 year age are widely affected by television viewing that encourage an unhealthy lifestyle and consumption of junk food is another factor that increases the risk of obesity(R. J. Hancox et. al. (2004)). The aggressive marketing of junk foods among the youngster promotes the obesity in the children. Apart from these factors, transportation is also involves in the development of obesity. These days, most of the kids reach to the school by bus rather than walking or cycling. Technology now takes the place over the physical activity that is the main reason to increase in rate of obesity in the children(M. Dehghan et. al. (2005)). By introducing the various extra curriculum activities in school as well as at home can help in reducing the time spending of watching television. Cycling and walking needs to be promoted in order to reduce the risk of obesity.

3. Overeating: The third factor that causes obesity in children is overeating. In many countries, most of the child's life affected by overeating. Schools are also promoting the unhealthy food choices among the children. Cafeteria/ canteens are serving unhealthy food with large content fat and low nutrition(L. Kempster et. al. (2005)). In a recent study, it has been noticed that consumption of fats and calories with large amount can decrease the consumption of vegetables and foods. In order to reduce the obesity problem in children due to overeating, society and food companies must ensure that promotion of fast and junk food must be less as possible so that children cannot attracts to junk foods. Schools also need to promote to serve healthy food rather than serving unhealthy food with less nutrition. The management of the school needs to monitor the food quality on daily basis. 


\section{Diagnosis}

1. Quantization of Body fat in childhood: Obesity occurs due to the excessive accumulation of the body fat. As the body fat increase, the morbidity is also increase resulting in health risks. It is difficult to measure the body fat directly. Based on the body mass index (BMI), the obesity can be easily estimated. By using BMI, the body fat can be estimated in both adults and children. According to the world health organization (WHO) guidelines, BMI of 25-30 $\mathrm{kg} / \mathrm{m} 3$ defines as overweight that causes obesity in adults. $\mathrm{BMI}$ can be used as a quantization factor for measuring of excessive weight.

2. Skinfold thickness: Measurement of skinfold thickness is a simple and quick method that can be used for different sites of the body. It doesn't required specialized skills; a trained person can do this measurement easily based on standardized measurement process. This method is suitable only for high body mass index (BMI). Triceps skinfold is correlated with the fat mass and in combination with BMI helps to improve the sensitivity for the estimation of body fat percentage(L. B. Sardinha et. al. (1999)). Skinfold thickness approach is not suitable for thin people (less weight), this is the major disadvantage associated with this approach.

3. Bioelectric impedance assay (BIA): BIA is quick and simple method as skinfold thickness method but BIA is expensive and noninvasive. BIA gives highly variable results because it is highly dependent on the meals, exercise and other factors that changes the hydration state of the body such as diseases related to kidneys, acute illness and menstrual phase(D.L. Thompson et. al. (1991)). The measuring quantity based on BIA approach is not suitable to get information on long term, because it is highly dependent on variable factors including meal and physical activity.

\section{Dual Energy X-ray absorptiometry (DEXA): DEXA} method is relatively expensive but very safe in order to estimate over all fat of the body. This method has high precision and accuracy. The exposure of x-ray to body is minimal. This method is mainly use for the research purpose. This method has one limitation; it cannot differentiate between visceral fat and sc.

4. Imaging: In order to estimate the visceral fat, computed tomography and magnetic resonance imaging (MRI) of the abdomen gives accurate information. The main drawback of this method is that it is very expensive and high exposure to radiation(P.R. Stanforth et. al. (2004)). For this method, a specialized person with skill can perform this task. That's why this method mostly used for the research purposes.

Treatment And Prevention Of Childhood Obesity: In order to prevent and treat the obesity problem, eat less and involvement in physical activity can play a crucial role. Long term weight loss is very difficult to achieve rather than continuously involve in those activities which doesn't let weight gain. Childhood obesity faces many hurdles as compared to obesity in adults due to the psychological and intellectual immaturity. Most of the healthcare professional recommend to parents and schools to take care of healthy lifestyle of the children by adapting the effective physical activity programs and healthy food(C. Doak et. al. (2002)).

1. Family based Approach: Based on family intervention in terms of parental support, family function and home surrounding can play a crucial role for treating childhood obesity in effective way. Family members need to encourage each other to involve in physical activity. Family based intervention outcomes are better than who receivedtherapy or treatment. A healthy home environment can encourage to children to follow healthy life style. Watching television or spending time on any electric gadgets must be within the limit. Parents must advice and teach to their kids to have healthy food. Family based intervention can reduce childhood obesity significantly(L.H. Epstein et. al. (2001)). In order to reduce the risk of obesity in children, family and home surroundings play a crucial role. Parents and family members needs to teach children about healthy lifestyle.

2. School-Based Approach: Physical education provided by schools can make effective efforts towards treatment of obesity in children. This can be achieved by means of involvement of students in games and sports. Various awareness programs and counseling can help to improve the impact over the mass level. The Active programme promoting lifestyle education in schools (APPLES) intervention launches various healthy lifestyle determinants such as improved and effective playground facilities, interesting extracurricular activities, and fitnessprograms, compulsion of providing healthy foods by cafeterias/ canteens. By implementation of the APPLES program, a significant increase in vegetables consumption has been observed by not achieved the targeted BMI(P. Sahota et. al. (2001)). School can promote physical activity by introducing the sports and games in the curriculum.

3. Pharmacological and surgical Treatments: In a study, ten randomized trials of pharmacological treatment have been done on obese children. Except one trial, all the pharmacological treatment was done in older children $(>$ 12 year age). The exception enrolled individuals aged 9-18 years. The two drugs: (i) orlistat and (ii) sibutramibne meets the pooled meta-analysis criteria in trials. An additional effect has been noticed compared to placebo when it gives in combination with lifestyle intervention was a difference in BMI of $-0.76 \mathrm{~kg} / \mathrm{m} 3$. On the other hand, an additional effect of sibutramine compared to the placebo when it given in combination with a lifestyle intervention was difference in BMI of $-1.66 \mathrm{~kg} / \mathrm{m} 3$ at six months (H. O. Luttikhuis et. al. (2009)). In order to understand long term outcomes, a random trial of orlistat performed, it shows a change in BMI of $-0.55 \mathrm{~kg} / \mathrm{m} 3$ with orlistat versus $0.31 \mathrm{~kg} / \mathrm{m} 3$ with placebo at twelve months. In an another one random trial of sibutramine, the researchers reported the change in BMI of $-2.9 \mathrm{~kg} / \mathrm{m} 3$ with sibutramine versus $-0.3 \mathrm{~kg} /$ $\mathrm{m} 3$ with placebo at twelve months(J.-P. Chanoine et. al. (2005)). No bariatric surgery has been done in children due to the psychological and physiological immaturity $(\mathrm{H}$. O. Luttikhuis et. al. (2009). 


\section{CONCLUSION}

Childhood obesity is the major health issue faced by the world due to the unhealthy lifestyle. There are various factors identified by the researchers that promote the obesity in the children including overeating, lack of exercise and genetics. Genetics contributed rarely in childhood obesity but other two factors have huge impact for promoting the obesity among the children. In order to prevent childhood obesity, school based intervention and family based intervention can help to reduce the risk of obesity in children. In order to take care of children's health, society and educational institutions must play a responsible role to promote awareness about healthy lifestyle.

\section{REFERENCES}

Chanoine, J.P., Hampl, S., Jensen, C., Boldrin, M. and Hauptman, J., 2005. Effect of orlistat on weight and body composition in obese adolescents: a randomized controlled trial. Jama, 293(23), pp.2873-2883.

Daniels, S.R., 2006. The consequences of childhood overweight and obesity. The future of children, 16(1), pp.47-67.

Daniels, S.R., 2009. Complications of obesity in children and adolescents. International journal of obesity, 33(1), pp.S60-S65.

Doak, C., Adair, L., Bentley, M., Fengying, Z. and Popkin, B., 2002. The underweight/overweight household: an exploration of household sociodemographic and dietary factors in China. Public health nutrition, 5(1a), pp.215221.

Grant-Guimaraes, J., Feinstein, R., Laber, E. and Kosoy, J., 2016. Childhood overweight and obesity. Gastroenterology Clinics, 45(4), pp.715-728.

Jadavji, N.M., 2006. Literature review-a 21st century epidemic: childhood obesity in North America. Journal of Young Investigators.

Kempster, L., 2004. Declaring war on obesity: A fight that can be won. Sarasota, FL: imerge consulting.

Lanigan, J., Tee, L. and Brandreth, R., 2019. Childhood obesity. Medicine, 47(3), pp.190-194.

LH, E., 2001. Roemmich JN, Raynor HA. Behavioral therapy in the treatment of pediatric obesity. Pediatr Clin N Am, 48, pp.981-93.

Moran, O. and Phillip, M., 2003. Leptin: obesity, diabetes and other peripheral effects-a LH, E., 2001. Roemmich $\mathrm{JN}$, Raynor HA. Behavioral therapy in the treatment of pediatric obesity. Pediatr Clin N Am, 48, pp.981-93.review. Pediatric diabetes, 4(2), pp.101-109.

Oniang'o, R., 2012. Comprehensive investment in women holds the key to child survival and to a healthy nation: Can MDGs help?.

RJ, H., 2015. Milne BJ. Poulton R. Association between child and adolescent television viewing and adult health: a longitudinal birth cohort study. Lancet, 10(364), p.9430.

Sahoo, K., Sahoo, B., Choudhury, A.K., Sofi, N.Y., Kumar, R. and Bhadoria, A.S., 2015. Childhood obesity. Causes and consequences. J Family Med Prim Care 4 (2): 187-192.

Sahota, P., Rudolf, M.C., Dixey, R., Hill, A.J., Barth, J.H. and Cade, J., 2001. Evaluation of implementation and effect of primary school based intervention to reduce risk factors for obesity. Bmj, 323(7320), p.1027.

Sardinha, L.B., Going, S.B., Teixeira, P.J. and Lohman, T.G., 1999. Receiver operating characteristic analysis of body mass index, triceps skinfold thickness, and arm girth for obesity screening in children and adolescents. The American journal of clinical nutrition, 70(6), pp.10901095.

SINGH, S., CARDIO-RESPIRATORY FITNESS IN RELATION TO BODY FAT PERCENTAGE.

Stanforth, P.R., Jackson, A.S., Green, J.S., Gagnon, J., Rankinen, T., Despres, J.P., Bouchard, C., Leon, A.S., Rao, D.C., Skinner, J.S. and Wilmore, J.H., 2004. Generalized abdominal visceral fat prediction models for black and white adults aged 17-65 y: the HERITAGE Family Study. International journal of obesity, 28(7), pp.925-932.

Thompson, D.L., Thompson, W.R., Prestridge, T.J., Bailey, J.G., Bean, M.H., Brown, S.P. and McDaniel, J.B., 1991. Effects of hydration and dehydration on body composition analysis: a comparative study of bioelectric impedance analysis and hydrodensitometry. The Journal of sports medicine and physical fitness, 31(4), pp.565-570.

Tremblay, M.S. and Willms, J.D., 2000. Secular trends in the body mass index of Canadian children. Cmaj, 163(11), pp.1429-1433.

Whitney, E.N. and Rolfes, S.R., 2002. Understanding nutrition 9th Edition. USA. RR Donnelley/Willard. 